\title{
Investigation of the Effect of IRAK1/4 Inhibitor on the Expression of P53, Bcl-2, Bax and GALNT14 Genes in Combination with Methotrexate and Topotecan in Breast Cancer Cell Lines
}

\author{
Mina Salarkarmi ${ }^{1,2}$ (D), Beydolah Shahouzehi ${ }^{3,4}$ (D), Samaneh Rahemi ${ }^{2}$ (D) , Hossein Fallah ${ }^{2, *(D)}$ \\ 1 Student Research Committee, Kerman University of Medical Sciences, Kerman, Iran; mina.salarkarimi2@gmail.com \\ (M.S.); \\ 2 Department of Biochemistry, Afzalipour School of Medicine, Kerman University of Medical Sciences, Kerman, Iran; \\ mina.salarkarimi2@gmail.com_(M.S.); s.rahemi93@yahoo.com (S.R.); hf59ma@gmail.com (F.H.); \\ 3 Cardiovascular Research Center, Institute of Basic and Clinical Physiology Sciences, Kerman University of Medical \\ Sciences, Kerman, Iran; b.shahozehi@kmu.ac.ir; bshahouzehi@gmail.com (B.S.); \\ 4 Physiology Research Center, Institute of Basic and Clinical Physiology Sciences, Kerman University of Medical Sciences, \\ Kerman, Iran; s.rahemi93@yahoo.com (S.R.); b.shahozehi@kmu.ac.ir; bshahouzehi@gmail.com (B.S.); \\ * Correspondence: hf59ma@gmail.com;
}

Received: 28.07.2020; Revised: 25.08.2020; Accepted: 28.08.2020; Published: 2.09.2020

Abstract: Breast cancer is the most common cancer among women. Chemotherapy is one of the main methods of breast cancer treatment, but its efficacy is affected by drug resistance. Interleukin-1 receptor-dependent kinases (IRAKs) are associated with drug resistance in cancer cells. The aim of this study was to investigate the relationship between the expression of p53, Bax, Bcl-2, and GALANT14 in treatment with Methotrexate and Topotecan alone and in combination with IRAK1/4 inhibitor. BT20, BT549, and MB468 breast cancer cell lines were cultured in a specific culture medium, and the effects of Methotrexate and Topotecan with or without IRAK1/4 inhibition on the expression of P53, Bcl-2, Bax, and GALNT14 genes was evaluated by Real-Time PCR. RT-qPCR results showed that the administration of IRAK1/4 inhibitor increased the expression of p53 in all three cell lines treated with Methotrexate and Topotecan. IRAK1/4 inhibitor increased the efficacy of Methotrexate and Topotecan on $\mathrm{p} 53$ gene expression. The expression level of the Bcl2 gene was significantly increased in the MB468 cell line treated with Topotecan and IRAK inhibitor + Methotrexate. In the present study, it was found that the IRAK1/4 inhibitor increased the efficacy of Methotrexate and Topotecan on p53 gene expression, thereby inducing apoptosis.

Keywords: Breast cancer; Drug resistance; Methotrexate; Topotecan; Apoptosis.

(C) 2020 by the authors. This article is an open-access article distributed under the terms and conditions of the Creative Commons Attribution (CC BY) license (https://creativecommons.org/licenses/by/4.0/).

\section{Introduction}

The most common cancer among women is breast cancer. It accounts for $29 \%$ of new cases and $14 \%$ of deaths from cancer .In 2017, more than 250,000 women were diagnosed with cancer, and it is estimated that more than 40,000 people will die from the disease $[1,2]$. Chemotherapy is one of the main ways to treat breast cancer, but the effectiveness of this treatment is affected by drug resistance and the lack of factors predicting resistance [1-4]. About $50 \%$ of cancer patients are resistant to treatment (intrinsic resistance) before receiving chemotherapy, and a large number of sensitive individuals become resistant to it after receiving 
the drug (acquired resistance) [5,6]. The phenomenon of multi-drug resistance (MDR), is defined as a process in which cancer cells become resistant to the drugs. In drug resistance in breast cancer, cells that respond to medications at the beginning of treatment recur and show resistance against many drugs [6-9]. Activation of the ATP binding cassette (ABC) transfer system in cancer is one of the most important mechanisms that cause drug resistance. In this way, the transfer of drugs to the outside of the cell is increased, thus reducing the concentration of the drug inside the cell [10].

Interleukin 1 receptor-dependent kinases (IRAKs) are one of the factors associated with drug resistance in cancer cells. IRAKs are key intermediaries in the process of transmitting messages from the Toll-Like Receptor (TLR) and the Interleukin 1 (IL1R) Receptor [10,11]. The role of the TLR / IL1R signaling pathway is to control various cellular processes such as inflammation, apoptosis, and cell differentiation. There are 4 IRAK genes (IRAK-1, IRAK-2, IRAK-3, and IRAK-4) in the human genome. The non-phosphorylated IRAK1 is attached to MYD88 through its death domain, and when it is phosphorylated, it is separated from MYD88 and eventually activates the NF-kB path [11]. In 1863, the link between inflammation and cancer was discovered that white blood cells migrated from the blood to tumors, and a number of other studies have shown the role of tumor-related macrophages in cancer progression and drug resistance $[11,12]$. Chronic inflammation increases the risk of cancer, and the IRAK family is used as a therapeutic target due to its role in signaling inflammatory pathways [11].

Topotecan is used as an anti-tumor and inhibitor of topoisomerase I in more than 70 countries as a second treatment for ovarian cancer and in more than 30 countries for the treatment of lung cancer. By binding to topoisomerase I and creating a complex on DNA, Topotecan breaks down the double-stranded DNA strand during replication and eventually leads to cell death as a result of apoptosis [13]. Methotrexate is an anti-metabolite drug that inhibits the enzyme Dihydrofolate Reductase (DHFR), eventually inhibiting replication and inducing apoptosis. However, unfortunately, due to the drug resistance created by cancer cells, its efficiency decreases [14].

Apoptosis is the most common programmed cell death mechanism. Many apoptotic stimuli exert their effects through a pathway that is regulated by family members of the Bcl-2 protein. These proteins act as inducers or inhibitors of cell death and interact with each other by formation of homodimer or heterodimer. For example, Bcl-2, Bcl-xl, and Mcl-i are antiapoptosis proteins that suppress apoptosis; therefore, they can interact with Bax as a proapoptotic protein and regulate apoptosis [15].

The P53 protein is a DNA replicator regulator and a tumor suppressor gene that suppresses the tumor by inducing cellular apoptosis. Inactivation of this gene leads to a reduction in apoptosis. Although overexpression is seen in breast cancer, it is a non-specific diagnostic marker due to its association with other tumors and indicates a poor prognosis. Loss of P53 function through gene deletion, mutation, or a combination of the both, occurs consistently in advanced breast cancer and is associated with poor clinical outcomes in some patients [15,16]. P53 can induce apoptosis in cells by suppressing Bcl-2 expression and stimulating Bax expression [17].

Glycosylation is one of the most common post-translational changes in more than half of the protein secreted and found in cells, and inappropriate glycosylation is closely related to tumor growth, metastasis, and resistance to chemotherapy $[18,19]$. N-glycosylation and Oglycosylation are the two main types of protein glycosylation in mammalian cells. The most common type of O-glycosylation is the transfer of $\mathrm{N}$-acetylgalactoseamine to the hydroxyl 
group of serine or threonine roots, which is catalyzed by a large family of $\mathrm{N}$ acetylgalactosaminyl transferase (GALNTs) containing at least 20 members in humans [20]. Among members of this family, GALNT14 regulates multi-drug resistance (MDR) in breast cancer. A high level of GALNT14 makes MCF-7 cells resistant to Adriamycin, while its removal sensitizes cells to Adriamycin. In addition, GALNT14 has been shown to increase Pgp stability and expression in cancer cells and induce drug resistance [21,22]. In our previous study, we concluded that IRAK1/4 inhibitor increases the sensitivity to Topotecan and Methotrexate drugs and increases the death of cells in three different cell types of breast cancer. In this study, we intend to: First, considering the potential effect of this inhibitor on the expression of genes involved in the induction or inhibition of apoptosis such as p53, Bcl-2, and Bax. Second, measure the inhibitory effect of IRAK1/4 on the expression of GALNT14, as a factor that regulates the stability of MDR proteins.

\section{Materials and Methods}

This research was approved by the ethics committee of Kerman University of Medical Sciences with no. "IR.KMU.1397.310".

\subsection{Cell culture and treatment.}

Human breast cancer cell lines BT-549, MDA-MB-468, and BT-20 were obtained from the Iranian Biological Research Center. All cells were cultured in a humidified atmosphere of $5 \% \mathrm{CO}_{2}$ at $37{ }^{\circ} \mathrm{C}$ and in their own dedicated culture media. The BT-549 cells were cultured in DMEM (Gibco, USA) medium and fetal bovine serum (FBS, Gibco,USA) $10 \%$ and 100 units/ml of penicillin, $100 \mu \mathrm{g} / \mathrm{ml}$ of streptomycin, and $2 \mathrm{mM} \mathrm{L-Glutamine.} \mathrm{The} \mathrm{BT-20} \mathrm{and}$ MDA-MB-468 cells were cultured in Ham's F12 (Gibco, USA) medium plus 2 mM LGlutamine and FBS $10 \%$, and 100 units $/ \mathrm{ml}$ of penicillin, and $100 \mu \mathrm{g} / \mathrm{ml}$ of streptomycin. For assessing the effect of IRAK1/4 inhibitor on gene expression, each cell line was treated with IRAK1/4 inhibitor $(1 \mu \mathrm{g} / \mathrm{ml})$ for $6,12,24,48$, and $72 \mathrm{~h}$. All cell lines in their specific medium were treated with Methotrexate $(1 \mu \mathrm{g} / \mathrm{ml})$ or Topotecan $(1 \mu \mathrm{g} / \mathrm{ml})$ with or without IRAK1/4 inhibitor $(1 \mu \mathrm{g} / \mathrm{ml})$ for $72 \mathrm{~h}[23]$.

\subsection{Quantitative real-time PCR.}

Total RNA from about three million cells of each cell line (BT-20, BT-549, MB-468) was extracted with the RNeasy mini kit (Qiagen, Germany) according to the manufacturer's guidelines. The RNA concentration was determined by the ultraviolet (UV) light absorbance at $260 \mathrm{~nm}$ and $280 \mathrm{~nm}$ (ND-1000 Nanodrop). The quality of RNA was confirmed by Ethidium bromide staining of $18 \mathrm{~S}$ and $28 \mathrm{~S}$ ribosomal RNA bands after electrophoresis in a $2 \%$ agarose gel. The sequences of the primers which were used in this study are listed in Table 1. Changes of expression were calculated by the equation: $2-\Delta \Delta \mathrm{CT}[23]$.

Table 1. Primer sequences used for real-time PCR.

\begin{tabular}{l|l|l} 
Gene & Forward primer $\left(5^{\prime} \rightarrow 3^{\prime}\right)$ & Reverse primer $\left(5^{\prime} \rightarrow 3^{\prime}\right)$ \\
\hline P53 & AGGGTTAGTTTACAATCAGC & GGTAGGTGCAAATGCC \\
\hline Bcl-2 & CTGCACCTGACGCCCTTCACC & CACATGACCCCACCGAACTCAAAGA \\
\hline Bax & GGGTGGTTGGGTGAGACTC & AGACACGTAAGGAAAACGCATTA \\
\hline GALNT14 & TAGCATCATCATCACCTTCCAC & TTACAGTCATCAGGGTCATTGC \\
\hline B.Actin & ATCAAGATCATTGCTCCTCCTGAG & CTGCTTGCTGATCCACATCTG
\end{tabular}




\subsection{Statistical analysis.}

All data are presented as mean \pm SEM. Statistical analyses were performed using the SPSS software version 20 for Windows. We used Mann-Whitney analysis to evaluate the differences between groups. $\mathrm{P}<0.05$ was considered statistically significant.

\section{Results and Discussion}

The expression of the P53 gene in any of the treated cell lines with IRAK1/4 inhibitor did not show a significant difference with the treatment period of $6,12,24$, and $72 \mathrm{~h}$ compared to the control group (Figure 1). The expression of the P53 gene in the group treated with Methotrexate and Topotecan and also in the combined use of these drugs with IRAK1/4 inhibitor compared to the control group in BT549 and MB468 cell groups showed a significant difference with the control group. However, the effect of these drugs alone in the BT20 cell line was not significantly different from the control group (Figure 2). Also, the use of the IRAK1/4 inhibitor increases the expression of the P53 gene in all three cell lines under treatment with Methotrexate and Topotecan (Figure 2). As you can see in figure 3, the expression of the GALNT14 gene only showed a significant increase in the BT20 cell line under treatment with IRAK1/4 inhibitors at 24 and $72 \mathrm{~h}$ compared to the control group. While in other groups, it did not show any significant difference compared to the control group. The expression of the GALNT14 gene in the MB468 cell line under treatment with IRAK1/4 inhibitor and Topotecan with $\mathrm{P}<0.01$ showed a significant increase. The expression of the GALNT14 gene was significantly higher when we used the combination of IRAK1/4 inhibitor and Methotrexate, as well as the combination of IRAK1/4 inhibitor and Topotecan when we treated the drug alone (Figure 4). The expression of the Bax gene in the BT549 cell line in the $24 \mathrm{~h}$ treatment and in the BT20 cell line at all times, except for 6 hours, showed a significant increase compared to the control group (Figure 5). As shown in Figure 6, the expression of the Bax gene when using Methotrexate in the MB468 and Topotecan cell line in all three lines, as well as in the combined use of these drugs with IRAK1/4 inhibitor, showed a significant difference compared to the control group.

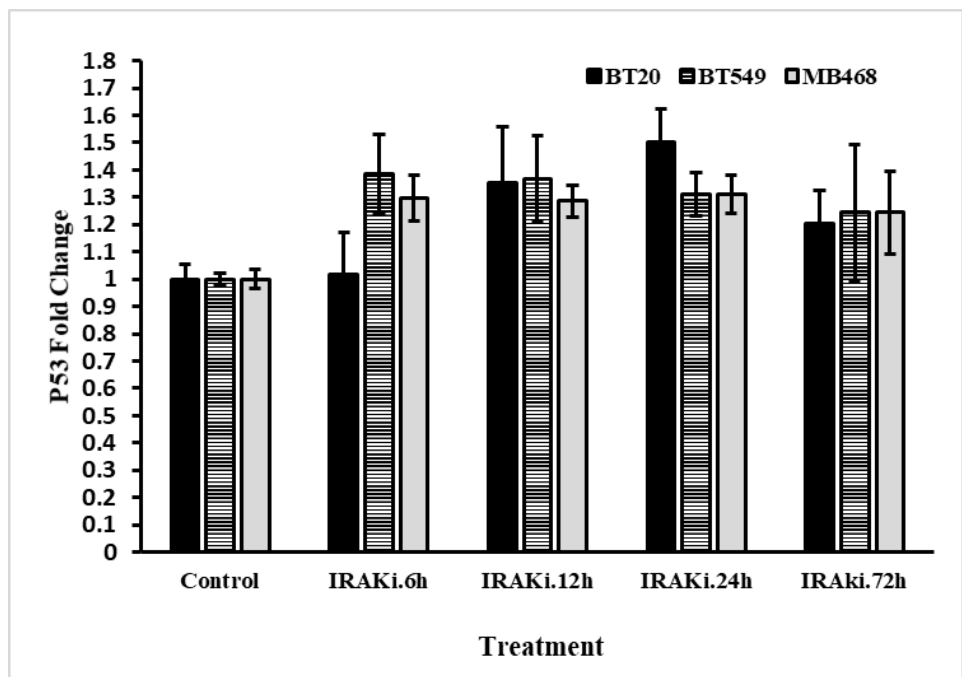

Figure 1. The inhibitory effect of IRAK1/4 inhibitor on the expression of the P53 gene in three cell lines: BT20, BT549, MB468. Cells BT549 and MB468 were cultured in DMEM medium and BT20 cell line in Hams F12 culture medium. Cells were treated with IRAK1/4 inhibitor $(1 \mu \mathrm{g} / \mu \mathrm{l})$ at $6,12,24$, and 72 hours. The results were obtained using a Real-time PCR technique and were reported to be partially related to the actin gene. Data are expressed as Mean \pm SEM. 
The expression of the Bax gene when we used the combination of IRAK1/4 inhibitor with Methotrexate and Topotecan was significantly more significant than when we treated the drug alone in the two cell line BT549 and MB468.

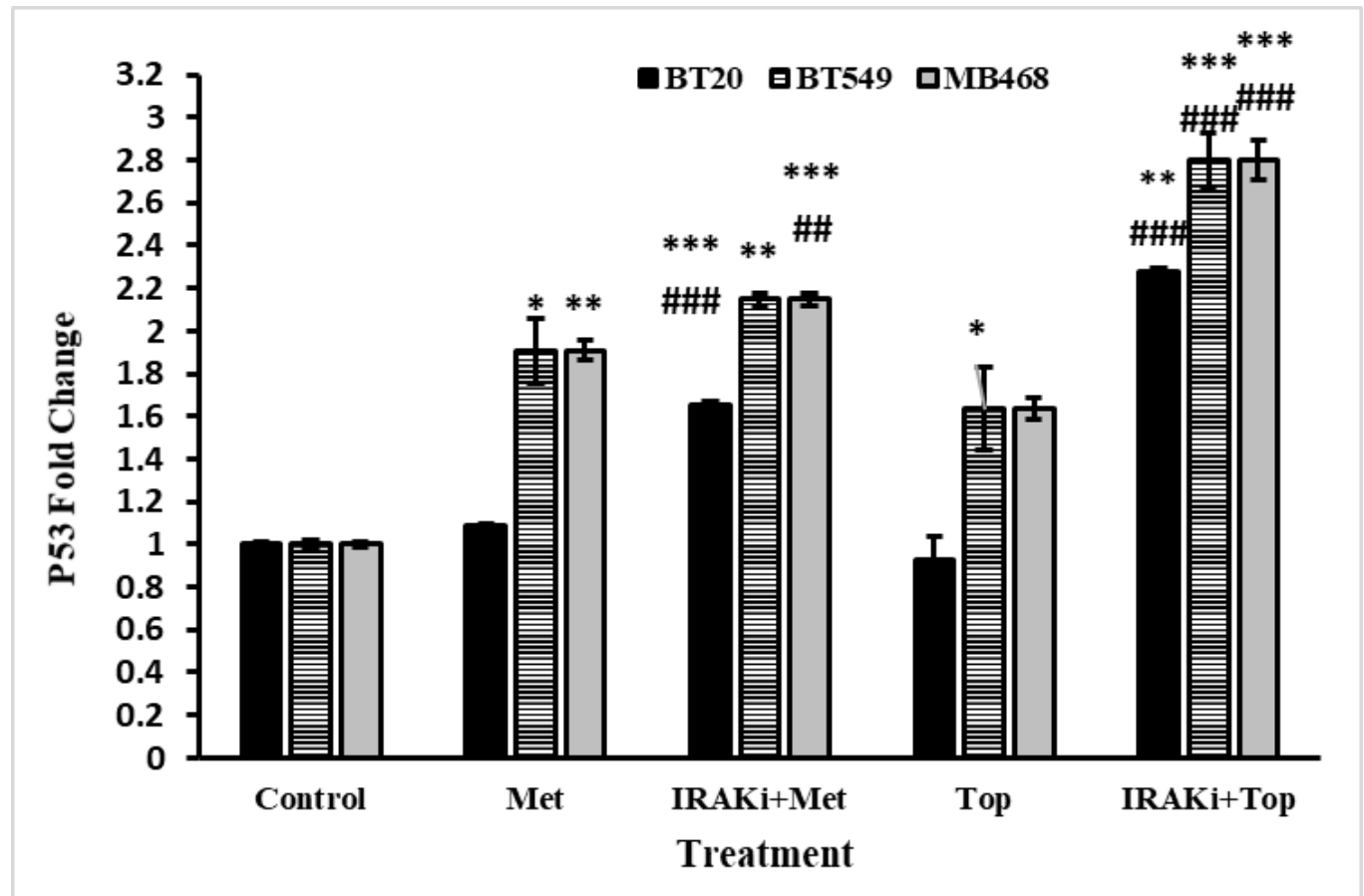

Figure 2. The effect of Methotrexate and Topotecan alone and in combination with IRAK1/4 inhibitor on expression of P53 gene in three cell lines BT20, BT549, MB468. Cells BT549 and MB468 were cultured in DMEM medium and BT20 cell line in Hams F12 culture medium. The cells were treated alone for 72 hours at a concentration of $1 \mu \mathrm{g} / \mathrm{ml}$ Methotrexate or Topotecan alone or in combination with IRAK1/4 inhibitor $(1 \mu \mathrm{g} / \mu \mathrm{l})$. The results were obtained using a Real-time PCR technique and were reported to be partially related to the actin gene. Data are expressed as Mean \pm SEM. $* \mathrm{P}<0.05 * * \mathrm{P}<0.01 * * * \mathrm{P}<0.0001$ show the difference compared to the control group and \# $\mathrm{P}<0.05$ \#\# $\mathrm{P}<0.01$ \#\#\# $\mathrm{P}<0.0001$ show the difference between the group treated with Methotrexate or Topotecan compared with the treatment group with the drug and IRAK1/4 inhibitor.

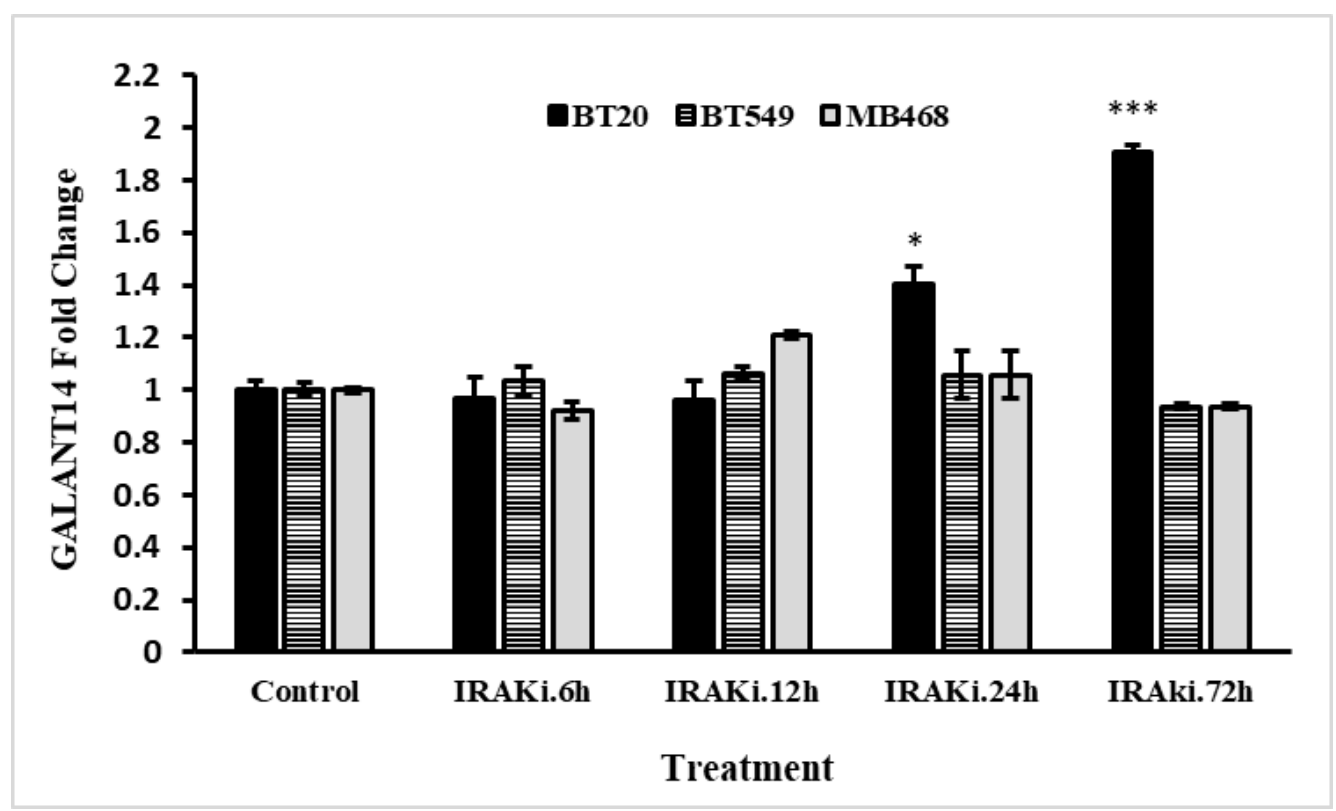

Figure 3. IRAK1/4 inhibitor effect on the expression of the GALNT14 gene in three cell lines BT20, BT549, MB468. Cells BT549 and MB468 were cultured in DMEM medium and BT20 cell line in Hams F12 culture medium. The cells were then treated alone for 72 hours at a concentration of $1 \mu \mathrm{g} / \mathrm{ml}$ Methotrexate or Topotecan alone or in combination with IRAK1/4 inhibitor $(1 \mu \mathrm{g} / \mu \mathrm{l})$. The results were obtained using a Real-time PCR technique and were reported to be partially related to the actin gene. Data are expressed as Mean \pm SEM. $* \mathrm{P}<0.05$ $* * \mathrm{P}<0.01 * * * \mathrm{P}<0.0001$ show the difference compared to the control group. 


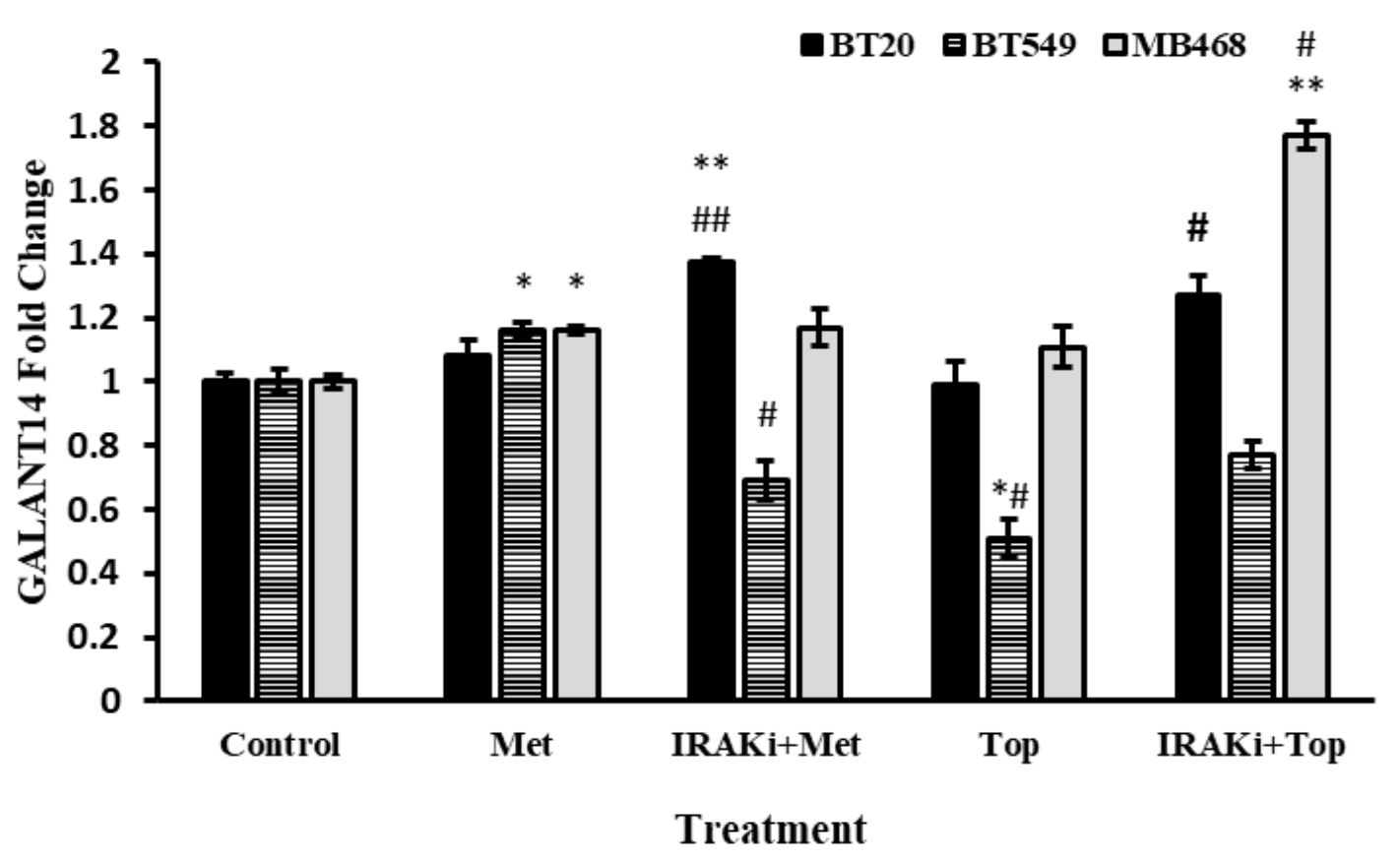

Figure 4. Effect of Methotrexate and Topotecan alone and in combination with IRAK1/4 inhibitor on gene expression in GALNT14 three cell lines BT20, BT549, MB468. Cells BT549 and MB468 were cultured in DMEM medium and BT20 cell line in Hams F12 culture medium. The cells were then treated alone for 72 hours at a concentration of $1 \mu \mathrm{g} / \mathrm{ml}$ Methotrexate or Topotecan alone or in combination with IRAK1/4 inhibitor $(1 \mu \mathrm{g} / \mu \mathrm{l})$. The results were obtained using a Real-time PCR technique and were reported to be partially related to the actin gene. Data are expressed as Mean \pm SEM. $* \mathrm{P}<0.05 * * \mathrm{P}<0.01 * * * \mathrm{P}<0.0001$ show the difference compared to the control group and \# $\mathrm{P}<0.05$ \#\# $\mathrm{P}<0.01$ \#\#\# $\mathrm{P}<0.0001$ show the difference between the group treated with Methotrexate or Topotecan compared with the treatment group with the drug and IRAK1/4 inhibitor.

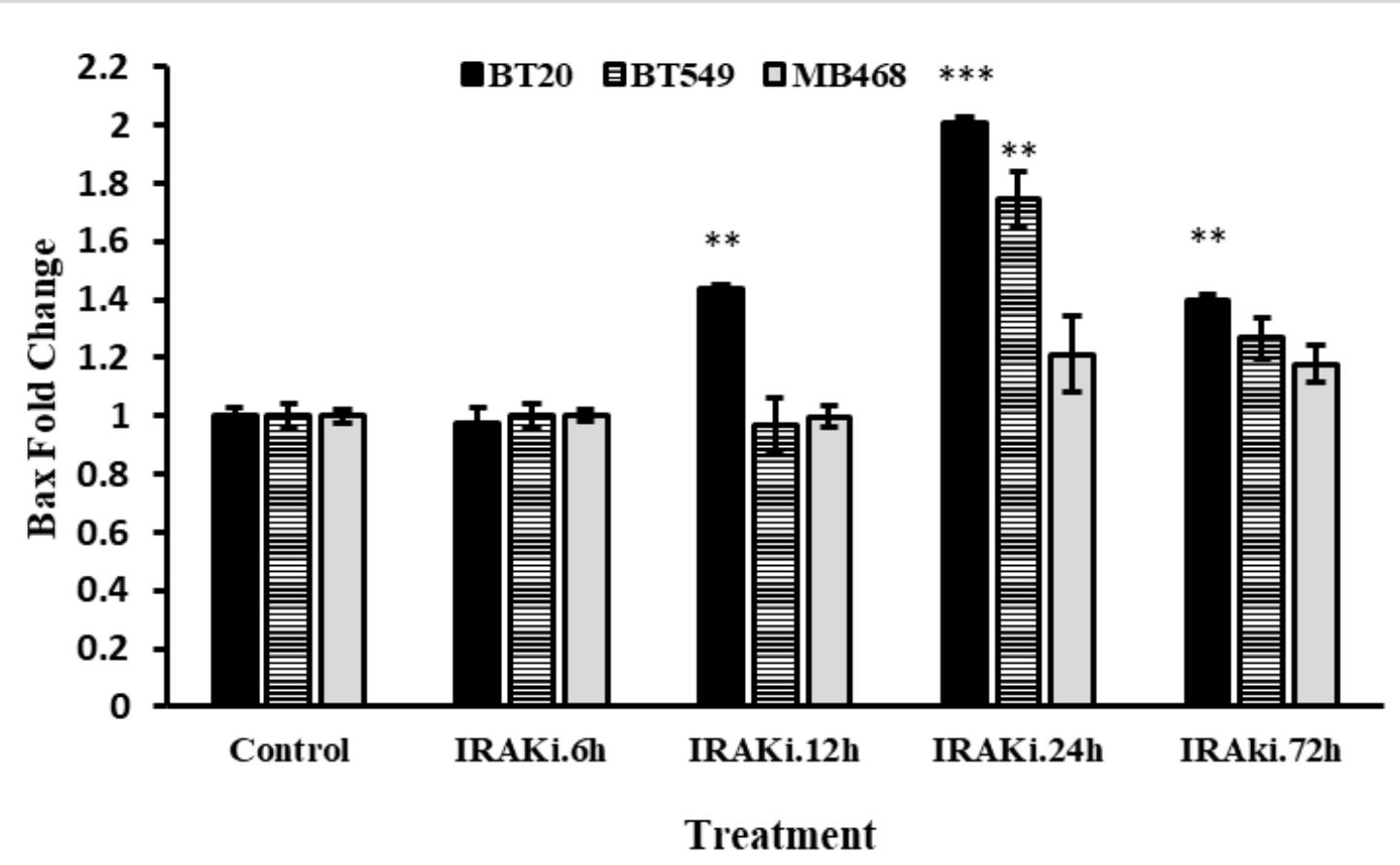

Figure 5. The inhibitory effect of IRAK1/4 inhibitor $(1 \mu \mathrm{g} / \mu \mathrm{l})$ on the expression of the Bax gene in three cell lines BT20, BT549, MB468. Cells BT549 and MB468 were cultured in DMEM medium and BT20 cell line in Hams F12 culture medium. The cells were then treated alone for 72 hours at a concentration of $1 \mu \mathrm{g} / \mathrm{ml}$ Methotrexate or Topotecan alone or in combination with IRAK1/4 inhibitor $(1 \mu \mathrm{g} / \mu \mathrm{l})$. The results were obtained using a Real-time PCR technique and were reported to be partially related to the actin gene. Data are expressed as Mean \pm SEM. * $\mathrm{P}<0.05 * * \mathrm{P}<0.01 * * * \mathrm{P}<0.0001$ show the difference compared to the control group. 


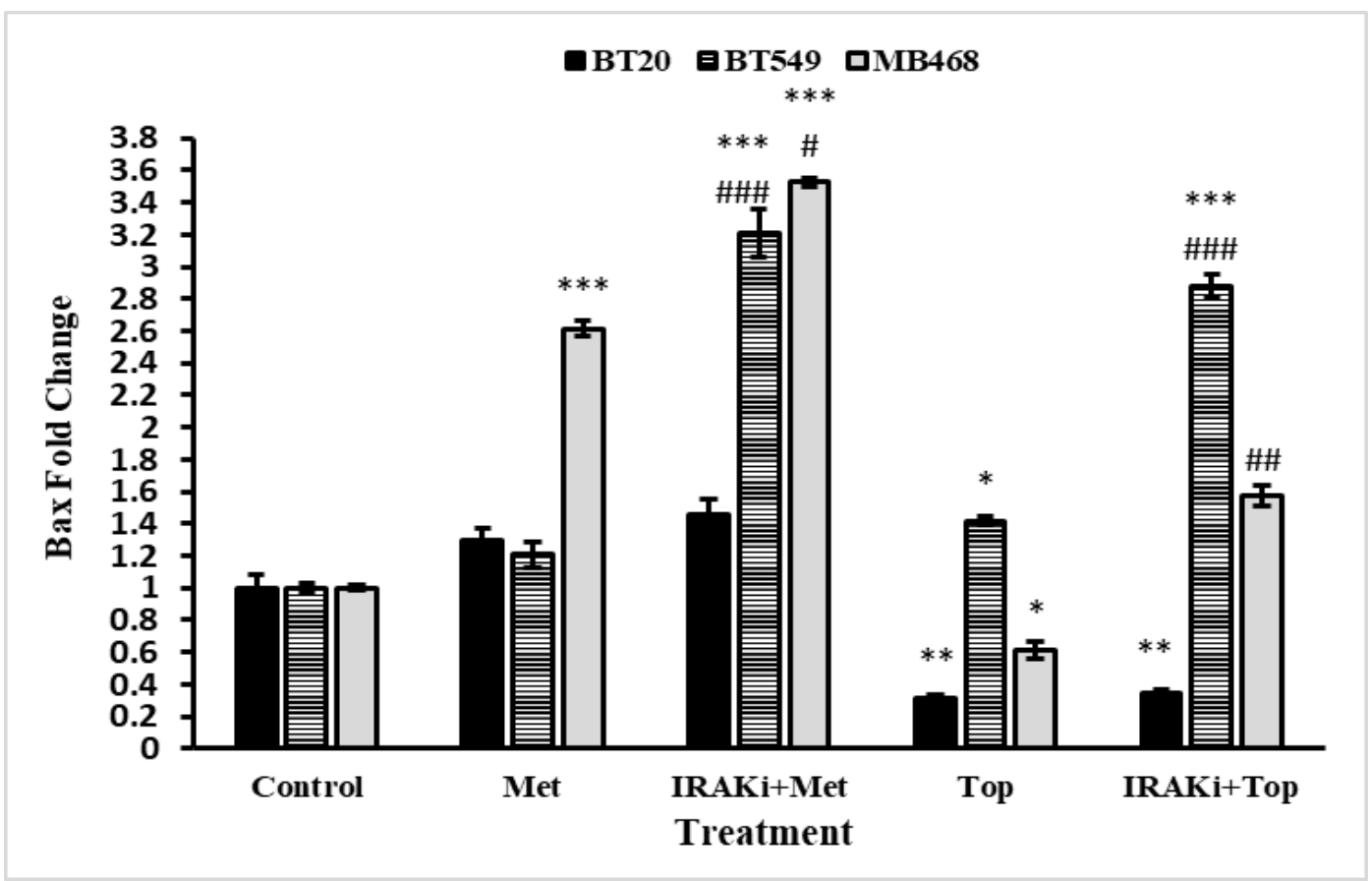

Figure 6. The effect of Methotrexate and Topotecan alone and in combination with IRAK1/4 inhibitor on Bax gene expression in three cell lines BT20, BT549, MB468. Cells BT549 and MB468 were cultured in DMEM medium and BT20 cell line in Hams F12 culture medium. The cells were then treated alone for 72 hours at a concentration of $1 \mu \mathrm{g} / \mathrm{ml}$ Methotrexate or Topotecan alone or in combination with IRAK1/4 inhibitor $(1 \mu \mathrm{g} / \mu \mathrm{l})$. The results were obtained using a Real-time PCR technique and were reported to be partially related to the actin gene. Data are expressed as Mean \pm SEM. $* \mathrm{P}<0.05 * * \mathrm{P}<0.01 * * * \mathrm{P}<0.0001$ show the difference compared to the control group and \# P $<0.05$ \#\# $\mathrm{P}<0.01$ \#\#\# $\mathrm{P}<0.0001$ show the difference between the group treated with Methotrexate or Topotecan compared with the treatment group with the drug and IRAK1/4 inhibitor.

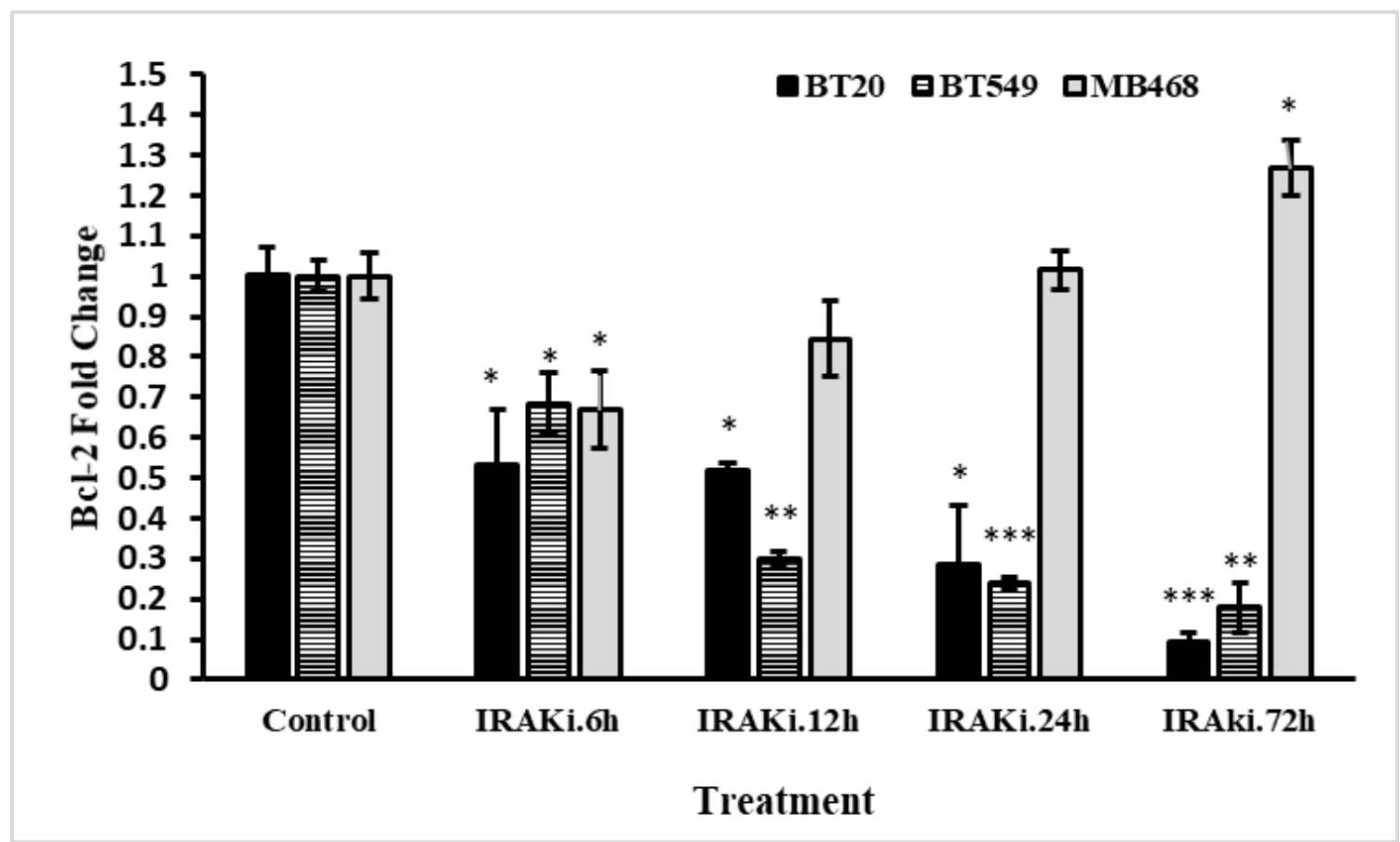

Figure 7. Effect of IRAK1/4 inhibitor $(1 \mu \mathrm{g} / \mu \mathrm{l})$ on the expression of the Bcl2 gene in three cell lines BT20, BT549, MB468. Cells BT549 and MB468 were cultured in DMEM medium and BT20 cell line in Hams F12 culture medium. The cells were then treated alone for 72 hours at a concentration of $1 \mu \mathrm{g} / \mathrm{ml}$ Methotrexate or Topotecan alone or in combination with IRAK1/4 inhibitor $(1 \mu \mathrm{g} / \mu \mathrm{l})$. The results were obtained using a Real-time $\mathrm{PCR}$ technique and were reported to be partially related to the actin gene. Data are expressed as Mean \pm SEM. ${ }^{*} \mathrm{P}$ $<0.05 * * \mathrm{P}<0.01 * * * \mathrm{P}<0.0001$ show the difference compared to the control group.

The expression of the Bcl-2 gene in the MB468 cell line and in the $72 \mathrm{~h}$ treatment compared to the control group increased significantly and did not change in the 24 and $12 \mathrm{~h}$ 
treatment and in the $6 \mathrm{~h}$ treatment compared with the control group showed a significant decrease (Figure 7). The expression of the Bcl-2 gene in the MB468 cell line under treatment with Topotecan and IRAK1/4 inhibitor + Methotrexate showed a significant increase compared to other groups. In the two treatment groups with Methotrexate and IRAK1/4 inhibitor + Topotecan, no significant change was observed compared to the control group (Figure 8).

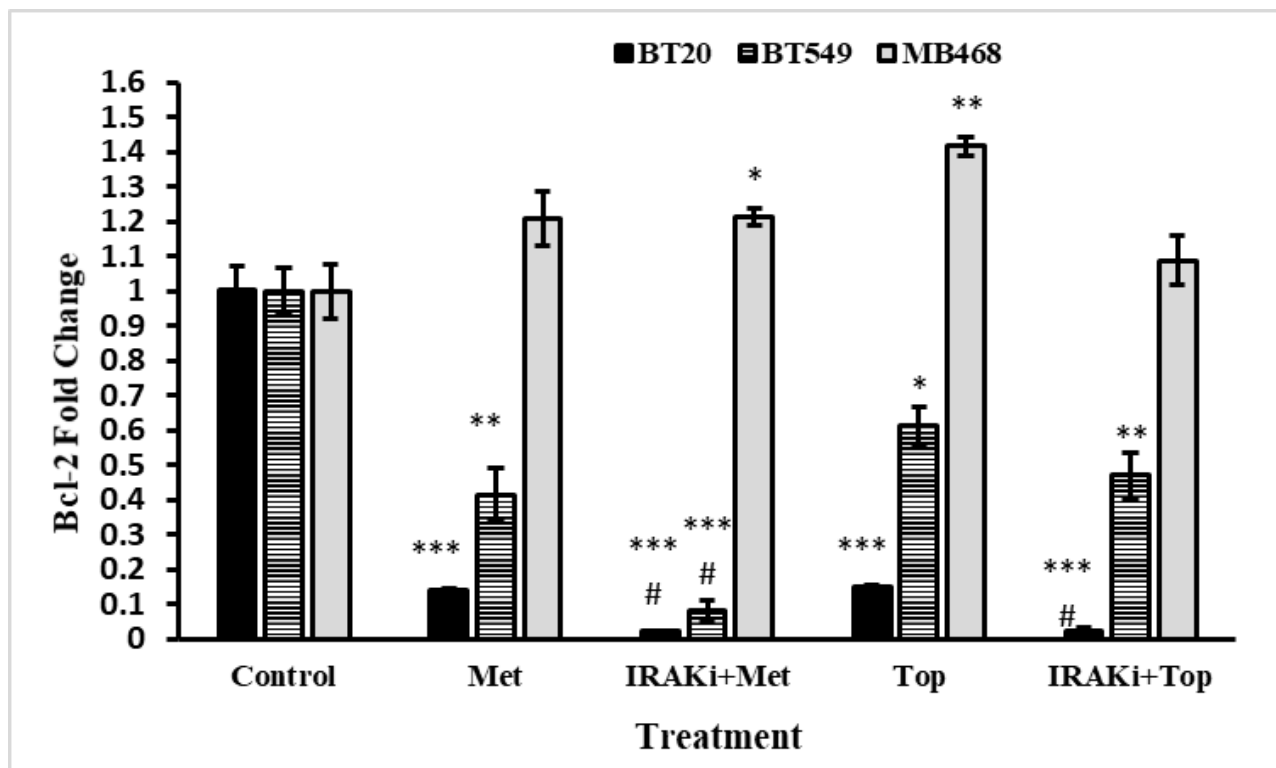

Figure 8. The effect of Methotrexate and Topotecan alone and in combination with IRAK1/4 inhibitor on Bcl-2 gene expression in three cell lines BT20, BT549, MB468. Cells BT549 and MB468 were cultured in DMEM medium and BT20 cell line in Hams F12 culture medium. The cells were then treated alone for 72 hours at a concentration of $1 \mu \mathrm{g} / \mathrm{ml}$ Methotrexate or Topotecan alone or in combination with IRAK1/4 inhibitor $(1 \mu \mathrm{g} / \mu \mathrm{l})$. The results were obtained using a Real-time PCR technique and were reported to be partially related to the actin gene. Data are expressed as Mean \pm SEM. $* \mathrm{P}<0.05 * * \mathrm{P}<0.01 * * * \mathrm{P}<0.0001$ show the difference compared to the control group and \# $\mathrm{P}<0.05$ \#\# $\mathrm{P}<0.01$ \#\#\# $\mathrm{P}<0.0001$ show the difference between the group treated with Methotrexate or Topotecan compared with the treatment group with the drug and IRAK1/4 inhibitor.



Figure 9. IRAK1/4 inhibitor effect $(1 \mu \mathrm{g} / \mu \mathrm{l})$ on Bax/Bcl-2 ratio in three cell lines BT20, BT549, MB468. Cells BT549 and MB468 were cultured in DMEM medium and BT20 cell line in Hams F12 culture medium. The cells were then treated alone for 72 hours at a concentration of $1 \mu \mathrm{g} / \mathrm{ml}$ Methotrexate or Topotecan alone or in combination with IRAK1/4 inhibitor $(1 \mu \mathrm{g} / \mu \mathrm{l})$. The results were obtained using a Real-time PCR technique and were reported to be partially related to the actin gene. Data are expressed as Mean \pm SEM. $* \mathrm{P}<0.05 * * \mathrm{P}<0.01$ *** $\mathrm{P}<0.0001$ show the difference compared to the control group and \# $\mathrm{P}<0.05$ \#\# $\mathrm{P}<0.01$ \#\#\# $\mathrm{P}<0.0001$ show the difference between the group treated with Methotrexate or Topotecan compared with the treatment group with the drug and IRAK1/4 inhibitor. 
The Bax / Bcl2 ratio in the MB468 cell line did not show a significant difference from the control group at all times; in other cell lines, it showed a significant increase compared to the control group (Figure 9). The Bax / Bcl2 ratio in the treatment with Methotrexate in the BT20 cell line and the treatment with IRAK1/4 inhibitor + Methotrexate and IRAK1/4 inhibitor + Topotecan in the BT20 and BT549 cell lines showed a significant increase compared to the control group, while In treatment with Topotecan in all three cell types and treatment with Methotrexate in two cell types MB468 and BT549, as well as treatment with IRAK1/4 inhibitor + Methotrexate did not show a significant change compared to the control group. Combining these drugs with IRAK1/4 inhibitors was significantly more significant than when we treated the drug alone in the BT20 and BT549 cell lines (Figure 10).



Figure 10. The effect of Methotrexate and Topotecan alone and in combination with IRAK1/4 inhibitor on Bax/Bcl-2 ratio in three cell lines BT20, BT549, MB468. Cells BT549 and MB468 were cultured in DMEM medium and BT20 cell line in Hams F12 culture medium. The cells were then treated alone for 72 hours at a concentration of $1 \mu \mathrm{g} / \mathrm{ml}$ Methotrexate or Topotecan alone or in combination with IRAK1/4 inhibitor $(1 \mu \mathrm{g} / \mu \mathrm{l})$. The results were obtained using a Real-time PCR technique and were reported to be partially related to the actin gene. Data are expressed as Mean \pm SEM. $* \mathrm{P}<0.05 * * \mathrm{P}<0.01 * * * \mathrm{P}<0.0001$ show the difference compared to the control group and \# $\mathrm{P}<0.05$ \#\# $\mathrm{P}<0.01$ \#\#\# $\mathrm{P}<0.0001$ show the difference between the group treated with Methotrexate or Topotecan compared with the treatment group with the drug and IRAK1/4 inhibitor.

Breast cancer, with about 1.7 million new cases and more than half a million deaths worldwide each year, is the leading cause of cancer mortality in women $[1,2,8]$. Chemotherapy is the most effective way to treat advanced cancers, but drug resistance and cancer metastases are two obstacles to successful chemotherapy. Multi-drug resistance includes intrinsic and acquired resistance, while post-chemotherapy metastases are associated with drug resistance. There are two main ways chemotherapy can kill cancer cells. One is the killing of cancer cells by exposing them directly to drugs, and the other is the induction of cancer cell suicide, or apoptosis [9]. We found that the IRAK1/4 inhibitor increased the expression of p53 in all three cell lines treated with Methotrexate and Topotecan. IRAK1/4 inhibitor increased the efficacy of Methotrexate and Topotecan on p53 gene expression. The effect of IRAK1/4 inhibitor in combination with Methotrexate and Topotecan on GALANT14 gene expression was significantly higher than treated drugs alone. The results of our study showed that IRAK1/4 inhibitors reduce the expression of the Bcl-2 gene in both BT20 and BT549 cell lines at all 
times. The two drugs, Topotecan and Methotrexate alone, and in combination with IRAK1/4 inhibitors, reduce the expression of the Bcl-2 gene in the BT20 and BT549 cell lines. These results suggest that inhibiting IRAK1/4 increases Bax expression and thus induces apoptosis. Also, the present study showed that the Bax/Bcl-2 ratio increases with IRAK1/4 inhibitor + Methotrexate and also by IRAK1/4 inhibitor + Topotecan in BT20 and BT549 cell lines. The results show that IRAK inhibition supports apoptosis.

Yang et al. (2019) showed that IRAK1 expression was decreased following neoadjuvant chemotherapy in patients with breast cancer and reduced the survival of the cancer cell as well as the size of the cancerous mass [24]. In another study by Zhang and colleagues (2014), elevated IRAK1 expression increased the risk of lung cancer and may be used as a target for the diagnosis and treatment of various cancers [35]. Wee and colleagues found that there was an $80 \%$ increase in IRAK-related mRNA expression in breast cancer cells, and an increase in IRAK1 expression played a role in creating resistance to Paclitaxel [26]. Effective and safe NFkB clinical inhibitors are not yet available [26], but there is a specific IRAK1/4 inhibitor as an effective suppressor in the NF- $\kappa \mathrm{B}$ signaling pathway, which its selective effect on cancer in breast cancer cell lines has been confirmed [26]. The results of another study on cervical cancer (HeLa) cells showed that inhibition of the NF- $\kappa B$ system, resulting in increased P53 expression, increased apoptosis in cancer cells [27-30]. Zhao et al. study showed that anticancer compound xanthohumol induced NF- $\kappa \mathrm{B}$ signaling inhibition and increased P53 expression, inducing induction of apoptosis in human liver cancer cells [28,29]. The present study showed that the IRAK1/4 inhibitor did not affect the expression of the P53 gene at any time, while the IRAK1/4 inhibitor increased the expression of the P53 gene in all three cell lines which treated with Methotrexate and Topotecan, plus IRAK inhibitor. IRAK inhibition increases the effectiveness of Methotrexate and Topotecan on P53 gene expression. The expression of the P53 gene in the BT20 cell line was lower in all four groups than in other cell lines. In the group treated with Topotecan, less significance was shown than in the other groups. The results suggest that increasing the expression of the P53 gene in all four groups compared to the control group increases the apoptosis process.

A 2019 study by Zhang et al. (2019) showed that Parkin increased the breakdown of TRAF6 and TRAF2 and inhibited NF- $\mathrm{BB}$, which eventually led to apoptosis in hepatocellular carcinoma [31]. A study by Li Binghui et al. showed that the treatment of colorectal cancer cells with Ginsenoside Rh2 activates the P53 pathway and increases the level of pro-apoptotic protein, Bax, while reducing the level of the anti-apoptotic protein Bcl-2 [32-34]. The results of a study conducted by Sharifi $\mathrm{S}$ et al. Showed that increasing the Bax/Bcl2 ratio and decreasing Caspase 9 levels could play a key role in the resistance of MCF-7 breast cells to paclitaxel [35]. We found in our study that two-cell lines of BT549 and MB468 treated with Topotecan increased the expression of the P53 gene and thus induced apoptosis. Also, Methotrexate and Topotecan reduced the expression of the Bcl-2 gene in the BT20 and BT549 cell lines.

MDR is a major barrier to the successful treatment of breast cancer; Excessive P-gp expression occurs in approximately 50\% of human cancers [36]. Some studies have shown that activation of NF- $\kappa \mathrm{B}$ alters the P-gp function [37]. Many studies have shown that NF- $\kappa \mathrm{B}$ can regulate P-gp expression in many solid and leukemia tumors and that NF- $\kappa \mathrm{B}$ inhibitors can reduce its expression [38]. A member of the large $\mathrm{N}$-acetylgalactosaminyl transferase family, GALNT-14, regulates multi-drug resistance (MDR) in breast cancer. High levels of GALNT14 cause cells to become resistant to drugs, which in turn reduces the effectiveness of drugs 
[21]. Shan et al. (2018) showed a new pathway that GALANT14 regulates P-gp stability for MDR. Their results show that GALANT14 increases P-gp glycosylation. Finally, GALANT14 is associated with high levels of P-gp in chemotherapy-resistant breast cancer tissues [21]. Our results showed that when we used IRAK1/4 inhibitor with Methotrexate in the BT20 cell line as well as IRAK1/4 inhibitor with Topotecan in the MB468 cell line, the expression of the GALANT14 gene increased relative to the control group, and also in comparison with drug retention. The treatment alone was significant, indicating the inhibitory effect of IRAK. Our results in this study are inconsistent with previous results because an increase in GALNT14 indicates resistance, possibly due to the fact that inhibitors from other pathways, such as decreased levels of inflammatory cytokines, increase drug sensitivity [21].

\section{Conclusions}

In the current study, it was found that the IRAK1/4 inhibitor increases the effectiveness of Methotrexate and Topotecan on the expression of the P53 gene, which in turn induces apoptosis. In combination with Topotecan and Methotrexate, the IRAK1/4 inhibitor reduces the expression of the Bcl-2 gene and increases the Bax expression and increases the Bax/Bcl2 ratio, which promotes apoptotic pathways. These findings support this hypothesis that IRAK1/4 inhibitor, in combination with anti-cancer drugs, promotes their efficacy and can be considered as a good new approach in cancer treatment, and this needs to be more evaluated in other cell lines and animal models.

\section{Funding}

This research was funded by Kerman University of Medical Sciences, grant number 97000289.

\section{Acknowledgments}

We would like to appreciate the Kerman Medical Unversity and Kerman Research Council's help and support in conducting this study.

\section{Conflicts of Interest}

The authors declare no conflict of interest.

\section{References}

1. Rong, G.; Kang, H.; Wang, Y.; Hai, T.; Sun, H. Candidate Markers That Associate with Chemotherapy Resistance in Breast Cancer through the Study on Taxotere-Induced Damage to Tumor Microenvironment and Gene Expression Profiling of Carcinoma-Associated Fibroblasts (CAFs). PLoS One 2013, 8, https://doi.org/10.1371/journal.pone.0070960.

2. Park, J.; Thomas, S.; Zhong, A.Y.; Wolfe, A.R.; Krings, G.; Terranova-barberio, M.; Pawlowska, V.; Benet, L.Z.; Munster, P.N. Local delivery of hormonal therapy with silastic tubing for prevention and treatment of breast cancer. Sci Rep 2018, 8, https://doi.org/10.1038/s41598-017-18436-1.

3. Filipits, M.; Pohl, G.; Rudas, M.; Dietze, O.; Lax, S.; Grill, R.; Pirker, R.; Zielinsky, C.C.; Hausmaninger, H.; Kubista, E.; Samonigg, H.; Jakesz, R. Clinical role of multi-drug resistance protein 1 expression in chemotherapy resistance in early-stage breast cancer: The Austrian Breast and Colorectal Cancer Study Group. J Clin Oncol 2005, 23, 1161-1168, https://doi.org/10.1200/jco.2005.03.033.

4. Wang, D.Y.; Lin, C.P.; Yeh, M.K. The recent development of gold nanoparticles in the applications of anticancer therapies and immunogenecity. Letters in Applied NanoBioScience 2016, 5, 335-341.

5. Lippert, T.H.; Ruoff, H.J.; Volm, M. Intrinsic and acquired drug resistance in malignant tumors: The main reason for therapeutic failure. Arzneimittel-Forschung. Drug Res 2008, 58, 261-264, https://doi.org/10.1055/s-0031-1296504. 
6. Khademalhosseini, M.; Arababadi, M.K. Toll-like receptor 4 and breast cancer: an updated systematic review. Breast Cancer 2019, 26, 265-271, https://doi.org/10.1007/s12282-018-00935-2.

7. Xu, F.; Wang, F.; Yang, T.; Sheng, Y.; Zhong, T.; Chen, Y. Differential drug resistance acquisition to doxorubicin and paclitaxel in breast cancer cells. Cancer Cell Int 2014, 14, https://doi.org/10.1186/s12935014-0142-4.

8. Jia, D.; Li, L.; Andrew, S.; Allan, D.; Li, X.; Lee, J.; Ji, G.; Yao, Z.; Gadde, S.; Figeye, D.; Wang, L. An autocrine inflammatory forward-feedback loop after chemotherapy withdrawal facilitates the repopulation of drug-resistant breast cancer cells. Cell Death Dis 2017, 8, https://doi.org/10.1038/cddis.2017.319.

9. Yu, Y.; Wang, Z.H.; Zhang, L.; Yao, H.J.; Zhang, Y.; Li, R.J.; Ju, R.J.; Wang, X.X.; Zhou, J.; Li, N.; Lu, W.L. Mitochondrial targeting topotecan-loaded liposomes for treating drug-resistant breast cancer and inhibiting invasive metastases of melanoma. Biomaterials 2012, 33, 1808-1820, https://doi.org/10.1016/j.biomaterials.2011.10.085.

10. Rubiś, B.; Hołysz, H.; Barczak, W.; Gryczka, R.; Łaciński, M.; Jagielski, P.; Czernikiewicz, A.; Półrolniczak, A.; Wojewoda, A.; Perz, K.; Białek, P.; Morze, K.; Kanduła, Z.; Lisiak, N.; Mrozikiewicz, P.M.; Grodecka-Gazdecka, S.; Rybczyńska, M. Study of ABCB1 polymorphism frequency in breast cancer patients from Poland. Pharmacol Reports 2012, 64, 1560-1566, https://doi.org/10.1016/s17341140(12)70954-4.

11. Rhyasen, G.W.; Starczynowski, D.T. IRAK signalling in cancer. Br J Cancer 2015, 112, 232-237, https://doi.org/10.1038/bjc.2014.513.

12. Yang, C.; He, L.; He, P.; Liu, Y.; Wang, W.; He, Y.; Du, Y.; Gao, F. Increased drug resistance in breast cancer by tumor-associated macrophages through IL-10/STAT3/bcl-2 signaling pathway. Med Oncol 2015, 32, https://doi.org/10.1007/s12032-014-0352-6.

13. Garst, J. Topotecan: An evolving option in the treatment of relapsed small cell lung cancer. Ther Clin Risk Manag 2007, 3, 1087-1095.

14. Volk, E.L.; Schneider, E. Wild-type breast cancer resistance protein (BCRP/ABCG2) is a methotrexate polyglutamate transporter. Cancer Res 2003, 63, 5538-5543.

15. Galluzzi, L.; Vitale, I. Molecular mechanisms of cell death: recommendations of the Nomenclature Committee on Cell Death. Cell Death and Differentiation 2018, 25, 486-541, https://doi.org/10.1038/s41418-017-0012-4.

16. Fisher, D.E. Apoptosis in cancer therapy: Crossing the threshold. Cell 1994, 78, 539-542, https://doi.org/10.1016/0092-8674(94)90518-5.

17. Yang, G.; Sau, C.; Lai, W.; Cichon, J.; Li, W. Sleep promotes branch-specific formation of dendritic spines after learning. Science 2014, 344, 1173-1178, https://doi.org/10.1126/science.1249098.

18. Lau, K.S.; Dennis, J.W. N-Glycans in cancer progression. Glycobiology 2008, 18, 750-760, https://doi.org/10.1093/glycob/cwn071.

19. Prajoko, Y.W.; Aryandono, T. The Effect of P-Glycoprotein ( P-gp ), Nuclear Factor-Kappa B ( Nf-kb ), and Aldehyde Dehydrogenase-1 (ALDH-1 ) Expression on Metastases, Recurrence and Survival in Advanced Breast Cancer Patients. Asian Pac J Cancer Prev 2019, 20, 1511-1518, https://doi.org/10.31557/APJCP.2019.20.5.1511.

20. Bennett, E,P,; Mandel, U.; Clausen, H.; Gerken, T.A.; Fritz, T.A.; Tabak, L.A. Control of mucin-type Oglycosylation: A classification of the polypeptide GalNAc-transferase gene family. Glycobiology 2012, 22, 736-756, https://doi.org/10.1093/glycob/cwr182.

21. Shan, J.; Liu, Y.; Wang, Y.; Li, Y.; Yu, X.; Wu, C. GALNT14 Involves the Regulation of Multidrug Resistance in Breast Cancer Cells. Transl Oncol 2018, 11, 786-793, https://doi.org/10.1016/j.tranon.2018.04.003.

22. Donmezm Y.; Gunduz, U. Reversal of multi-drug resistance by small interference RNA (siRNA) in doxorubicin-resistance MCF-7 breast cancer cells. Biomedicine \& Pharmacotherapy 2010, 65, 85-89, https://doi.org/10.1016/j.biopha.2010.12.007.

23. Rahemi, S.; Nematollahi-Mahani, S.N.; Rajaie, A.; Fallah, H. Inhibitor of Interleukin-1 Receptor-associated Kinases 1/4, Can Increase the Sensitivity of Breast Cancer Cells to Methotrexate. IJMCM 2019, 8, https://doi.org/10.22088/IJMCM.BUMS.8.3.200.

24. Yang, M.; Qin, X.; Qin, G.; Zheng, X. The role of IRAK1 in breast cancer patients treated with neoadjuvant chemotherapy. Onco Targets Ther 2019, 12, 2171-2180, https://doi.org/10.2147/OTT.S185662.

25. Zhang, X.; Dang, Y.; Li, P.; Rong, M.; Chen, G. Expression of IRAK1 in lung cancer tissues and its clinicopathological significance : a microarray study. Int J Clin Exp Pathol 2014, 7, 8096-8104.

26. Wee, Z.N.; Yatim, S.M.J.M.; Kohlbauer, V.K.; Feng, M.; Goh, J.Y.; Yi, B.; Lee, P.L.; Zhang, S.; Wang, P.P.; Lim, E.; Tam, W.L.; Cai, Y.; Ditzel, H.J.; Hoon, D.S.B.; Tan, E.Y.; Yu, Q. IRAK1 is a therapeutic target that drives breast cancer metastasis and resistance to paclitaxel. Nat Commun 2015, 6, 1-15, https://doi.org/10.1038/ncomms9746.

27. Priyadarsini, R.V.; Murugan, R.S.; Maitreyi, S.; Ramalingam, K.; Karunagaran, D.; Nagini, S. The flavonoid quercetin induces cell cycle arrest and mitochondria-mediated apoptosis in human cervical cancer ( HeLa ) cells through p53 induction and NF- $\kappa$ B inhibition. Eur $J$ Pharmacol 2010, 649, 84-91, https://doi.org/10.1016/j.ejphar.2010.09.020. 
28. Ruan, L. MiR-16-5p inhibits breast cancer by reducing AKT3 to restrain NF- $\kappa$ B pathway. Biosci Rep 2019 , 39 (8), BSR20191611. Https://doi.org/10.1042/BSR20191611.

29. Zhao, X.; Huang, X. Anti-cancer effect of xanthohumol induces growth inhibition and apoptosis of human liver cancer through NF- $\kappa$ B / p53-apoptosis signaling pathway. Oncol Rep 2016, 35, 669-675, https://doi.org/10.3892/or.2015.4455.

30. Li, X.; Guo, S.; Xiong, X.K.; Peng, B.Y.; Huang, J.M.; Chen, M.F.; Wang, F.Y.; Wang, J.N. Combination of quercetin and cisplatin enhances apoptosis in OSCC cells by downregulating XIAP through the NF- $\kappa \mathrm{B}$ pathway. J Cancer 2019, 10, 4509-4521, https://dx.doi.org/10.7150\%2Fjca.31045.

31. Zhang, X.; Lin, C.; Song, J.; Chen, H.; Chen, X.; Ren, L.; Zhou, Z.; Pan, J.; Yang, Z.; Bao, W.; Ke, X.; Yang, J.; Liang, Y.; Huang, H.; Tang, D.; Jiang, L.; Liu J. Parkin facilitates proteasome inhibitor-induced apoptosis via suppression of NF- $\kappa \mathrm{B}$ activity in hepatocellular carcinoma. Cell Death Dis 2019, 10, https://doi.org/10.1038/s41419-019-1881-X.

32. Li, B.; Zhao, J.; Wang, C.Z.; Searle, J.; He, T.C.; Yuan, C.S.; Du, W Ginsenoside Rh2 induces apoptosis and paraptosis-like cell death in colorectal cancer cells through activation of p53. Cancer Lett 2011, 301, 185-192, https://doi.org/10.1016/j.canlet.2010.11.015.

33. Cai, L.; Li, C.; Chen, W.; Qiu, Y.; Guo, Y.; Li, R. Penta-acetyl geniposide induces apoptosis of fibroblastlike synoviocytes from adjuvant-induced arthritis rats in vitro, associated with inhibition of NF- $\mathrm{k} B$ activation. Pharmacol Reports 2019, 71, 1006-1013, https://doi.org/10.1016/j.pharep.2019.05.014.

34. Ma, Q.; Wang, Y.; Song, A.L. Withaferin-A Inhibits Growth of Drug-Resistant Breast Carcinoma by Inducing Apoptosis and Autophagy, Endogenous Reactive Oxygen Species ( ROS ) Production, and Inhibition of Cell Migration and Nuclear Factor kappa B ( Nf- k B )/ Mammalian Target of Rapa. Med SCi Monit 2019, 25, 6855-6863, https://doi.org/10.12659/MSM.916931.

35. Sharifi, S.; Barar, J.; Hejazi, M.S.; Samadi, N. Roles of the Bcl-2 / Bax Ratio, Caspase-8 and 9 in Resistance of Breast Cancer Cells to Paclitaxel. Asian Pac J Cancer Prev 2014, 15, 8617-8622, https://doi.org/10.7314/apjcp.2014.15.20.8617.

36. Zhang, X.; Wu, X.; Li, J.; Sun, Y.; Gao, P.; Zhang, C.; Zhang, H.; Zhou, G. MDR1 (multi-drug resistance 1) can regulate GCS (glucosylceramide synthase) in breast cancer cells. J Surg Oncol 2011, 104, 466-471, https://doi.org/10.1002/jso.21958.

37. Pradhan, M.; Bembinster, L.A.; Baumgarten, S.C.; Frasor, J. Proinflammatory cytokines enhance estrogendependent expression of the multi-drug transporter gene ABCG2 through estrogen receptor and NFkB cooperativity at adjacent response elements. $J$ Biol Chem 2010, 285, 31100-31106, https://doi.org/10.1074/jbc.M110.155309.

38. Gu, K.S.; Chen, Y. Mechanism of P-glycoprotein expression in the SGC7901 human gastric adenocarcinoma cell line induced by cyclooxygenase-2. Asian Pacific J Cancer Prev 2012, 13, 2379-2383, https://doi.org/10.7314/APJCP.2012.13.5.2379. 